\title{
Acceleration of bone union by in situ- formed hydrogel containing bone morphogenetic protein-2 in a mouse refractory fracture model
}

Shintaro Shoji ${ }^{1}$, Kentaro Uchida ${ }^{1,2^{*}} \mathbb{D}$, Wataru Satio ${ }^{1}$, Hiroyuki Sekiguchi ${ }^{2}$, Gen Inoue ${ }^{1}$, Masayuki Miyagi ${ }^{1}$, Ken Takata', Yuji Yokozeki ${ }^{1}$ and Masashi Takaso ${ }^{1}$

\begin{abstract}
Background: An enzymatic crosslinking strategy using hydrogen peroxide and horseradish peroxidase is receiving increasing attention for application with in situ-formed hydrogels (IFHs). Several studies have reported the application of IFHs in cell delivery and tissue engineering. IFHs may also be ideal carrier materials for bone repair, although their potential as a carrier for bone morphogenetic protein (BMP)-2 has yet to be examined. Here, we examined the effect of an IFH made of hyaluronic acid (IFH-HA) containing BMP-2 in promoting osteogenesis in a mouse refractory fracture model.
\end{abstract}

Methods: Immediately following a fracture procedure, animals either received no treatment (control) or an injection of IFH-HA/PBS or IFH-HA containing $2 \mu \mathrm{g}$ BMP-2 (IFH-HA/BMP-2) into the fracture site ( $n=16$, each treatment).

Results: Fracture sites injected with IFH-HA/BMP-2 showed significantly greater bone volume, bone mineral content, and bone union compared with sites receiving no treatment or treated with IFH-HA/PBS alone (each $n=10$ ). Gene expression levels of osteogenic markers, Alpl, Bglap, and OsX, were significantly raised in the IFH-HA/BMP-2 group compared to the IFH-HA/PBS and control groups (each $n=6$ ).

Conclusion: IFH-HA/BMP-2 may contribute to the treatment of refractory fractures.

Keywords: In situ-formed hydrogels, Hyaluronic acid, Bone morphogenetic protein, Refractory fracture

\section{Background}

Approximately 5 to $10 \%$ of fractures show poor healing because of delayed or non-union at the fracture site $[1,2]$. When this arises, functional disabilities can result due to complications including pseudoarthrosis and skeletal deformities [3]. However, there are currently no effective treatments for refractory fractures. The use of bioactive

\footnotetext{
* Correspondence: kuchida@med.kitasato-u.ac.jp

1 Department of Orthopedic Surgery, Kitasato University School of Medicine, 1-15-1 Minami-ku, Kitasato, Sagamihara City, Kanagawa 252-0374, Japan ${ }^{2}$ Shonan University of Medical Sciences Research Institute, Nishikubo 500, Chigasaki City, Kanagawa 253-0083, Japan
}

materials that encourage bone formation and healing may improve intractable fracture healing.

One method used to increase the speed of fracture healing involves local application of growth factors [4-6]. For example, BMP-2, a potent osteoinductive cytokine, has the ability to induce bone and cartilage formation. However, because BMP-2 is only diffused via local administration, concerns have been raised regarding side effects such as attenuation of osteogenic potential and ectopic ossification $[7,8]$. Therefore, growth factor delivery systems that sustain the release of BMP-2 at fracture sites are

(c) The Author(s). 2020 Open Access This article is licensed under a Creative Commons Attribution 4.0 International License, which permits use, sharing, adaptation, distribution and reproduction in any medium or format, as long as you give appropriate credit to the original author(s) and the source, provide a link to the Creative Commons licence, and indicate if changes were made. The images or other third party material in this article are included in the article's Creative Commons licence, unless indicated otherwise in a credit line to the material. If material is not included in the article's Creative Commons licence and your intended use is not permitted by statutory regulation or exceeds the permitted use, you will need to obtain permission directly from the copyright holder. To view a copy of this licence, visit http://creativecommons.org/licenses/by/4.0/ The Creative Commons Public Domain Dedication waiver (http://creativecommons.org/publicdomain/zero/1.0/) applies to the data made available in this article, unless otherwise stated in a credit line to the data. 
necessary to improve the success of bone healing and to limit possible side effects.

Implantable carriers such as absorbable collagen sponge or hydroxyapatite have been used to aid fracture healing in clinical settings. However, because these biomaterials require surgical incision for implantation, the method is invasive [9]. In contrast, injectable materials have the advantage of being less invasive than implantable materials. However, injectable materials generally diffuse only from the injection site compared to implantable materials [10]. Therefore, a material that is injectable and has the advantages of implantable materials may be an ideal candidate for a BMP-2 carrier.

An enzymatic crosslinking strategy using hydrogen peroxide $\left(\mathrm{H}_{2} \mathrm{O}_{2}\right)$ and horseradish peroxidase (HRP) is receiving increasing attention for application with in situ-formed hydrogels (IFHs) made of natural polysaccharides, such as dextran, pullulan, and hyaluronic acid (HA) [11]. IFHs have suitable properties for biomedical application, including good cytocompatibility, tunable reaction rate, and substrate specificity [12-15]. Several studies have reported the application of IFHs in cell delivery and tissue engineering for bone or cartilage repair [12-16]. IFHs may also be ideal carrier materials for bone repair, although their potential as a carrier for BMP-2 has yet to be examined.

Glycosaminoglycans (GAGs) have been shown to improve BMP-2 bioactivity, including for obtaining the intended osteogenesis effects [17]. HA, a type of GAG, comprises linear polysaccharides made up of repeating disaccharide units of amino sugars and uronic acid, and is among the most used materials for enhancing the microenvironment for BMP-induced osteogenesis.

Here, we examined the effect of an IFH made of HA (IFH-HA) containing BMP-2 for promoting osteogenesis in a mouse refractory fracture model.

\section{Methods \\ Preparation of hyaluronic acid (HA)-tyramine (TA) conjugate}

The HA-TA conjugate was synthesized according to previously published methods $[12,18]$. Briefly, TA (final concentration $12.5 \mathrm{mM}$; FUJIFILM Wako Pure Chemical Corporation, Osaka, Japan) was dissolved in $25 \mathrm{mM} 50$ $\mathrm{kDa}$ HA solution (Kewpie Corporation Fine Chemical Division, Tokyo, Japan), and $2.5 \mathrm{mM}$ 1-ethyl-3-(3dimethylaminopropyl) carbodiimide hydrochloride (FUIFILM Wako Pure Chemical Corporation) and $2.5 \mathrm{mMN}$ hydroxysuccinimide (FUJIFILM Wako Pure Chemical Corporation) were added to start the conjugation reaction. Addition of $0.1 \mathrm{M} \mathrm{NaOH}$ was used to maintain the $\mathrm{pH}$ at 4.7 throughout the reaction. After stirring overnight at room temperature, the $\mathrm{pH}$ of the solution was raised to 7.0 , and the solution was subsequently placed in dialysis tubes with a molecular cutoff of $1 \mathrm{kDa}$. Dialysis was performed in the tubes against $100 \mathrm{mM}$ solution of sodium chloride for 2 days, a distilled water and ethanol mixture (3:1) for 1 day, and distilled water for 1 day. HA-TA was finally obtained by lyophilizing the purified solution.

\section{IFH-HA}

IFH-HA was prepared by cross-linking HA-TA polymer in the presence of horseradish peroxidase (HRP; FUJIFILM Wako Pure Chemical Corporation), as the catalyzing enzyme, and $\mathrm{H}_{2} \mathrm{O}_{2}$ in $10 \mathrm{mM}$ phosphate-buffered saline (PBS; pH 7.4). Briefly, HA-TA polymer solution (final concentration $2 \% \mathrm{w} / \mathrm{v}$ ) was combined with 0.8 units/mL HRP solution (final concentration 0.8 units/ $\mathrm{mL}$ ) containing $2 \mu \mathrm{g}$ BMP-2 (IFH-HA/BMP-2; PEPROTECH, Inc. Rocky Hill, NJ, USA) or PBS (IFH-HA/PBS) and $\mathrm{H}_{2} \mathrm{O}_{2}$ solution (final concentration $4 \mathrm{mM}$ ). Thus, the initial IFH-HA aqueous solution was cured through the $\mathrm{HRP}-\mathrm{H}_{2} \mathrm{O}_{2}$ reaction (approximately $10 \mathrm{~s}$ ).

\section{Sustained release of BMP-2 in vitro}

To evaluate the sustained release of BMP-2 from IFH$\mathrm{HA}, \mathrm{H}_{2} \mathrm{O}_{2}$ solution containing HA-TA and HRP solution containing $2 \mu \mathrm{g}$ BMP-2 were added to a $0.5-\mathrm{mL}$ plastic microcentrifuge tube. After curing IFH-HA, $200 \mu \mathrm{l}$ of PBS was added to the tube. To determine the release of BMP-2 from IFH-HA, BMP-2-loaded microtubes were incubated in $200 \mu \mathrm{l}$ of PBS for $1,4,6,24,48$, and $96 \mathrm{~h}$, and 1,2 , and 3 weeks. The supernatant was collected and stored at $-30^{\circ} \mathrm{C}$ until assay. The supernatant could not be collected after 6 weeks because the boundary between the gel and PBS was unclear. The concentration of BMP-2 in the supernatant was determined using the BMP-2 ELISA kit (R\&D Systems, Inc., Minneapolis MN, USA). The experiment was repeated 5 times $(n=5)$.

\section{Mouse refractory fracture model}

The femur fracture model was generated using 9-weekold C57BL/6 J mice [19]. The mice were maintained at Nippon Charles River Laboratories (Kanagawa, Japan) in a semi-barrier system under controlled temperature (23 $\left.\pm 28^{\circ} \mathrm{C}\right)$, humidity $(55 \pm 10 \%)$, and lighting (12-h light/ dark cycle), and received standard rodent chow (CRF-1; Oriental Yeast, Tokyo, Japan). The refractory fracture model was generated by making a $10-\mathrm{mm}$ incision in the lateral side of the left thigh under sterile conditions. The patella was medially dislocated by making a 4-mm lateral parapatellar incision. Following drilling of a $0.5-\mathrm{mm}$ hole into the intercondylar notch, a stainless steel needle $(0.5$ $\mathrm{mm}$ in diameter) was retrogradely inserted into the intramedullary canal. Osteotomy was conducted using a wire saw $(0.22 \mathrm{~mm}$ in diameter) via a small lateral approach, and insertion of a stainless steel needle into the 
intramedullary canal was used to stabilize the fracture. The entire circumference of an approximately $3-\mathrm{mm}$ width of periosteum centered on the fracture site, except for the medullary space, was ablated using a bipolar electrocautery (AARON940, Bovie Medical Corporation, NY, USA) at a power setting of $1.2 \mathrm{~W}$ for $10 \mathrm{~s}$ to obtain an intractable fracture. Our preliminary study showed that a non-cauterized model achieved union at 4 weeks. In contrast, in the refractory fracture model, poor bone formation was observed in the cauterized region, and nonunion continued to be observed until 6 weeks after facture (Additional File 1). Therefore, this model was used as the refractory model in this study. Immediately following the fracture, $25 \mu \mathrm{l}$ of IFH-HA/PBS or IFH-HA containing $2 \mu \mathrm{g}$ BMP-2 (IFH-HA/BMP-2) was injected around the fracture using a microsyringe to ensure exposure of the entire fracture site and was subsequently stabilized around the injected site with curing (each $n=$ 16). Animals that did not receive any treatment were used as controls $(n=16)$. Femurs from each of 10 mice in the control, IFH-HA/PBS, and IFH-HA/BMP-2 groups were used for micro-CT and histological analysis. The remaining 6 femurs in each group were analyzed by real time PCR analysis. All experimental procedures were performed in a blinded manner, with investigators blinded to the group assignment of each mouse. All animal experiments were conducted based on the guidelines of the Animal Ethics Committee of Kitasato University (approval number 2018-084).

\section{Determination of new bone volume and bone mineral content}

All mice were sacrificed 6 weeks after treatment. Femurs along with the surrounding muscle were removed and fixed in $4 \%$ paraformaldehyde at $4{ }^{\circ} \mathrm{C}$ for $48 \mathrm{~h}$. The femurs were moved into PBS and imaged on a micro- focus X-ray CT system (inspeXio SMX-90CT; Shimadzu, Tokyo, Japan) using a $90 \mathrm{kV}$ acceleration voltage, 110 $\mathrm{mA}$ current, $20 \mathrm{~lm} /$ pixel voxel size, and $1024 \times 1024$ matrix size. Using the micro-CT images of whole femur, new bone volume and bone mineral content were quantified in a 3-mm region (cauterized region) of interest centered on the fracture site (150 slices) chosen at the mid femur for each animal using a three-dimensional (3D) image analysis software (Tri-3D-Bon; Ratoc System Engineering, Tokyo, Japan), as previously described. Regions of new bone were determined using a threshold density of $300 \mathrm{mg} / \mathrm{cm}^{3}[10,19]$.

\section{Histology}

After micro-CT analysis, the femurs were submerged in a carboxymethyl cellulose (CMC) gel and then placed in hexane, and subsequently frozen using solid $\mathrm{CO}_{2}$. The frozen blocks were attached to a CM 3050S IV cryomicrotome (Leica Instruments, Heidelberger, Germany) and cut using a disposable tungsten carbide blade in a cryochamber maintained at $-25^{\circ} \mathrm{C}$. The cut surface was covered with a Cryofilm (Finetec, Tokyo, Japan), and any air bubbles forming behind the film were removed using a brush. The blocks were cut into sections of $6-\mu \mathrm{m}$ thickness using the tungsten carbide blade and dried at $-25^{\circ} \mathrm{C}$. Serial sections were stained with Von Kossa stain (Kureha Special Laboratory Co., Ltd., Tokyo, Japan). The area of new bone formed in a 3-mm region (cauterized region) of interest centered on the fracture site was quantified using the freehand tracing tool in ImageJ version 1.52 (National Institutes of Health, Bethesda, MD) $(n=10)$.

\section{Real time PCR}

Six weeks after the fracture, we harvested calluses from the fracture site from the three groups $(n=6)$. Total

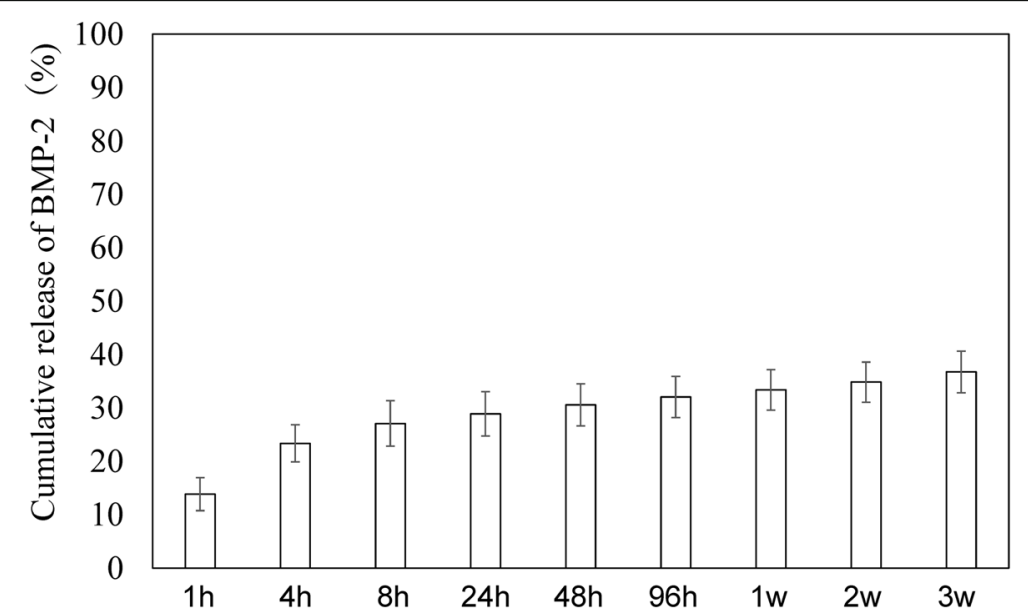

Fig. 1 Sustained release of BMP-2 from IFH-HA in vitro. Cumulative release of BMP-2 in PBS at different time points. Results are presented as mean \pm standard error $(\mathrm{SE})(n=5)$ 


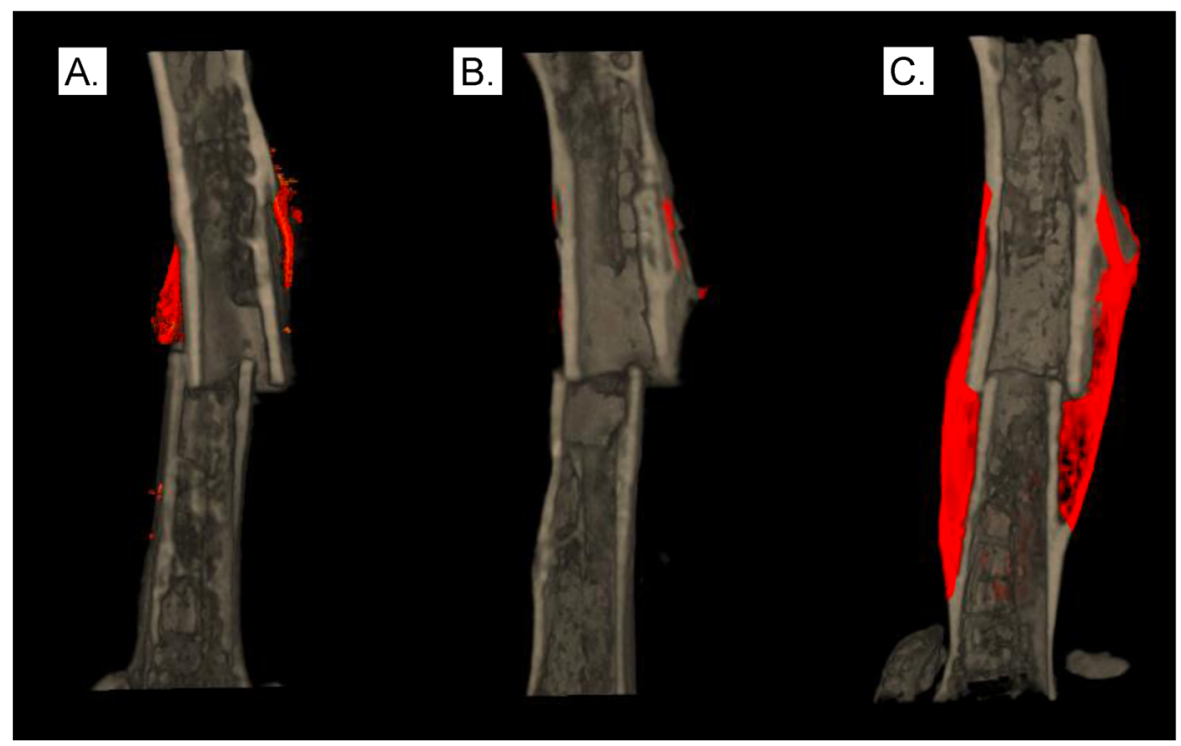

\section{control IFH-HA/PBS IFH-HA/BMP-2}

Fig. 2 Representative 3D micro-CT image of femurs after injection of in situ-formed hyaluronic acid hydrogel (IFH-HA) loaded with BMP-2. 3D micro-CT images of fractured femurs from a control, $\mathbf{b}$ IFH-HA/PBS-, and $\mathbf{c}$ IFH-HA/BMP-2-treated groups after 6 weeks of recovery. Red, newly formed bone; gray, existing bone. Scale bars indicate $3 \mathrm{~mm}$

RNA was extracted from calluses, and first-strand cDNA synthesis using SuperScript III RT (Invitrogen) was performed as described previously [20]. Gene expression of osteogenic markers, alkaline phosphatase (Alpl), osteocalcin (Bglap), and osterix (Osx), in callus was examined using real-time PCR. The following primers, designed using the Primer Blast software and synthesized by Hokkaido System Science Co. (Sapporo, Japan), were used for quantitative PCR: Alpl-sense 5'-CCACTATGTCTGGAACCGCA-3' and $A l p l$-antisense 5'-GAGAGCGAAGGGTCAGTCAG3' (product size $132 \mathrm{bp}$ ); Bglap-sense 5'-AGTGTGAGCT TAACCCTGCT-3' and Bglap-antisense 5'-ATAGATGC GTTTGTAGGCGGT-3' (product size 74.bp); Osx $x$-sense 5'-GCTGCGGGTATCCTGACTCT-3' and Osx -antisense
5' -CGGTGGTAGTTACGGTCGG-3' (product size 187 bp); Gapdh-sense 5'-AACTTTGGCATTGTGGAAGG-3', and Gapdh-antisense 5'-ACACATTGGGGGTAGGAA CA-3' (product size $223 \mathrm{bp}$ ). Levels of messenger (m)RNA for each gene of interest were normalized against levels of Gapdh using the delta-delta Ct method.

\section{Statistical analysis}

Differences among the control, IFH-HA/PBS, and IFHHA/BMP-2 groups were examined using one way ANOVA with post hoc analysis (Tukey's multiple comparison's test). A $P$ value of $<0.05$ was considered statistically significant. Statistical analysis was performed using the SPPSS software (Version 25.0; SPSS, IBM, Armonk, NY, USA).
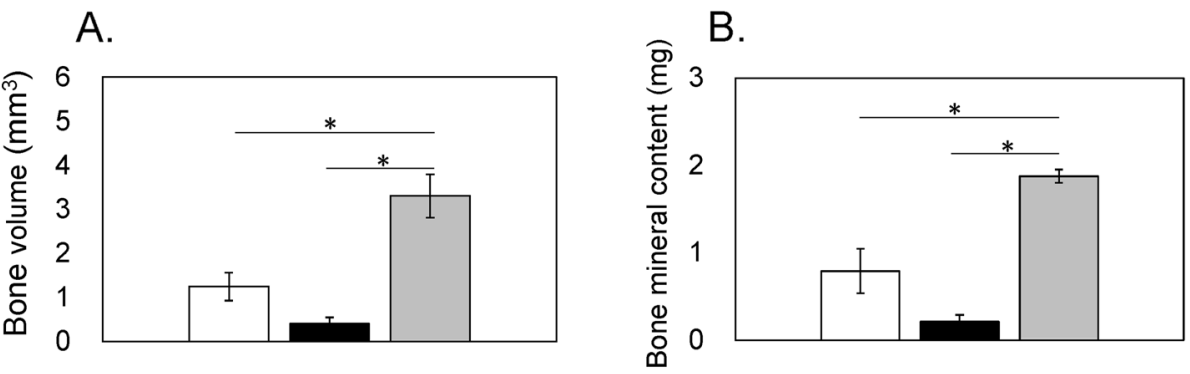

control

Fig. 3 Quantification of the callus area and bone mineral content at the cauterized region in the fracture site 6 weeks after creation of the fracture. Analysis of a bone volume $\left(\mathrm{mm}^{3}\right)$ and $\mathbf{b}$ bone mineral content (mg) in calluses from control (white bars), IFH-HA/PBS- (black bars), and IFH-HA/BMP-2-treated (gray bars) groups. Data are presented as the mean \pm SE $(n=10) .{ }^{*} p<0.05$ compared with the control group 


\section{Results}

Sustained release of BMP-2 from IFH-HA in vitro

The in vitro release profile of BMP-2 from IFH-HA is shown in Fig. 1. BMP-2 release from HA gel occurred with an initial burst in the first $4 \mathrm{~h}$ followed by a gentler release pattern after $8 \mathrm{~h}$. Thereafter, the sustained release rate was moderate, with $37 \%$ of the administered dose of BMP-2 gradually released across 3 weeks.

HA gel containing BMP-2 induced callus formation in vivo We evaluated callus formation in fractured femurs following treatment with IFH-HA containing BMP-2 using micro-CT image analysis 6 weeks post-treatment (Figs. 2 and 3). Compared to sites that received no treatment (control) or treated with IFH-HA alone, fracture sites injected with IFH-HA/BMP-2 showed significantly greater bone volume and bone mineral content $(P<0.05)$. In contrast, bone volume and bone mineral content were comparable between the IFH-HA and control groups.

\section{Histomorphometric findings}

To evaluate bone union, we conducted histological examination of the fracture site 6 weeks post-fracture (Fig. 4a-f). The IFH-HA/BMP-2-treated group exhibited large calluses at the fracture site compared to the IFHHA and control groups $(P<0.05$, Fig. $4 \mathrm{~g})$, and the
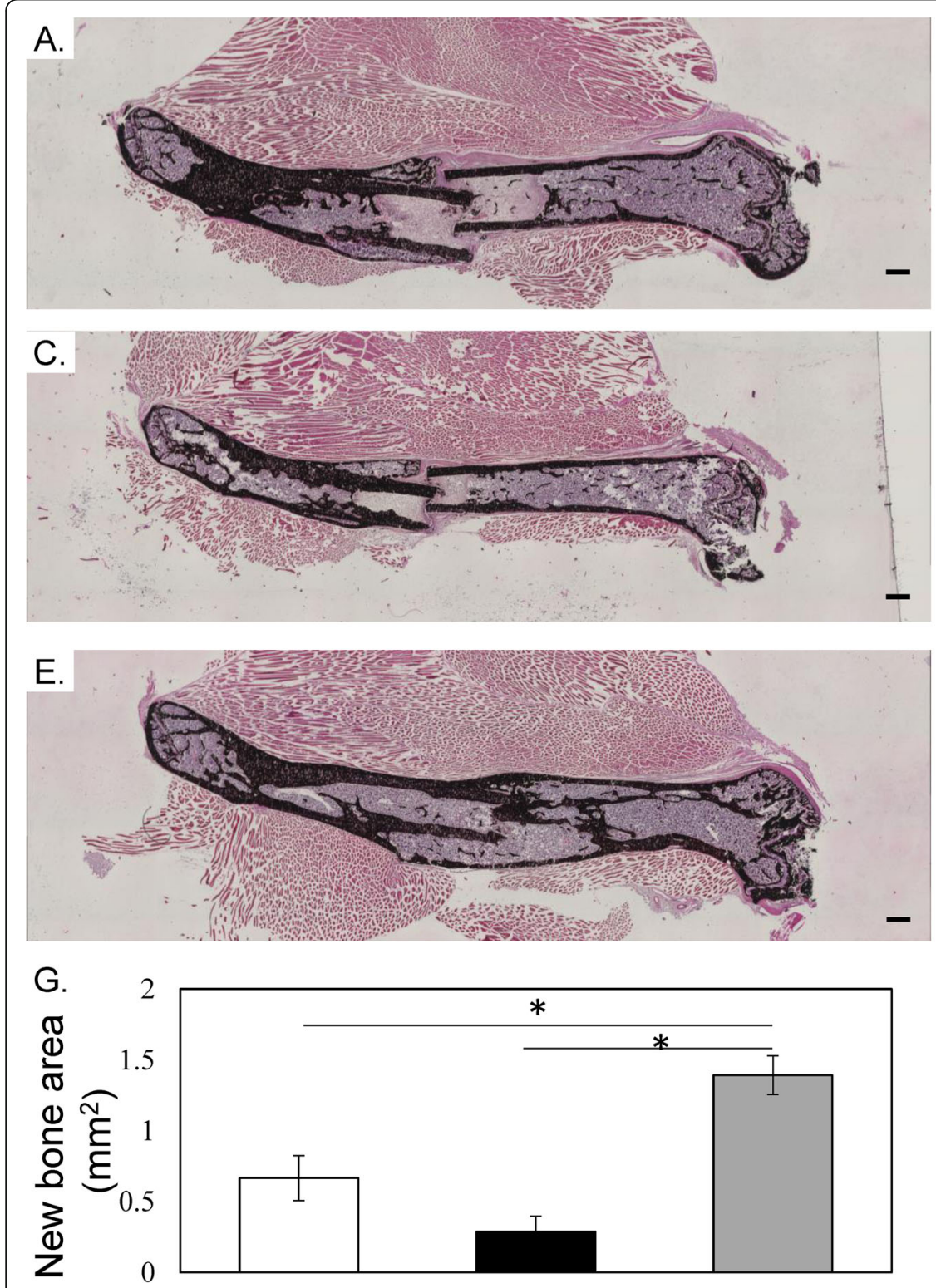
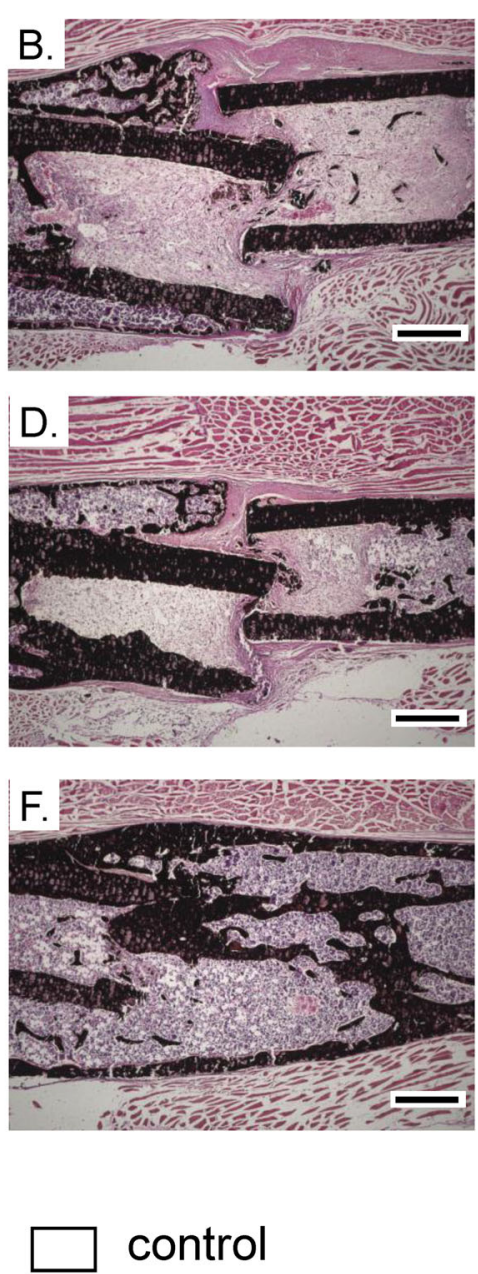

IFH-HA/PBS

IFH-HA/BMP-2

Fig. 4 Von Kossa staining of undecalcified fresh-frozen sections of femur and surrounding muscle. Von Kossa staining of a, b control; $\mathbf{c}$, $\mathbf{d}$ IFH-HA/ PBS; and e, f IFH-HA/BMP-2. g Quantification of new bone at fracture sites. ${ }^{*} p<0.05$. Scale bars indicate $500 \mu \mathrm{m}$. ${ }^{*} p<0.05$ 
A.

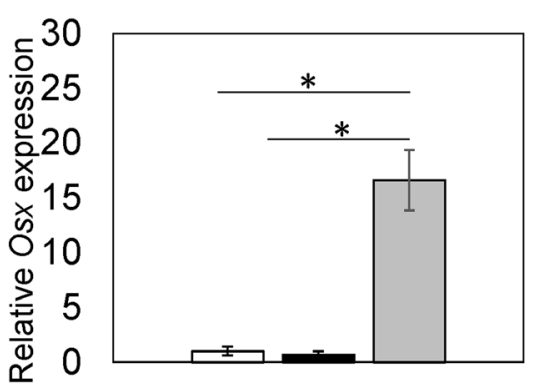

control
B.

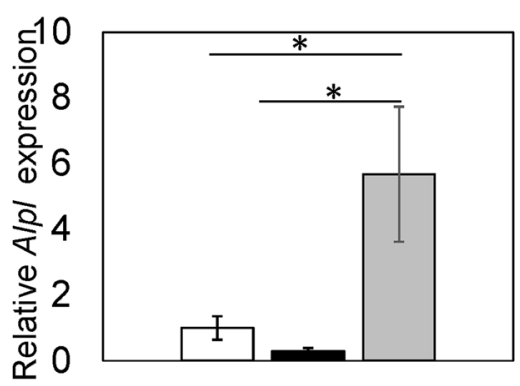

C.

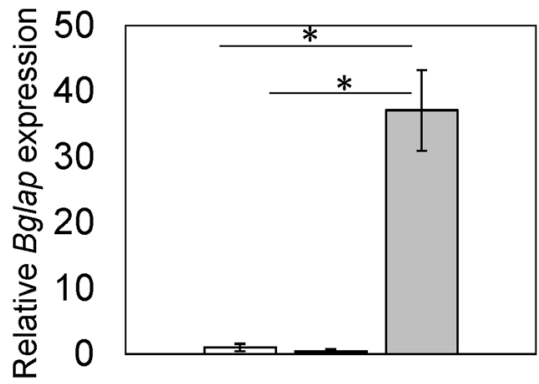

from control (white bars), IFH-HA/PBS- (black bars), and IFH-HA/BMP-2-treated (gray bars) groups $(n=6)$

fracture site was bridged by newly formed bone (Fig. 4f). In contrast, in the IFH-HA and control groups, fibrous or cartilage callus tissue were observed at the fracture site, and there was no evidence of bone union (Fig. $4 \mathrm{~d}$, e).

\section{Expression of Alpl, Bglap, and Osx}

Gene expression levels of osteogenic makers, Alpl, Bglap, and Osx, were significantly raised in the IFHHA/BMP-2 group compared to the IFH-HA and control groups (Fig. 5a, b, c; $P<0.05$ ). Meanwhile, Alpl, Bglap, and Osx levels were comparable between the IFH-HA and control groups $(P<0.05)$.

\section{Discussion}

Several studies have examined HA hydrogels for their potential as carriers for BMP-2. Injectable or implantable HA hydrogels retain BMP-2 and stimulate bone formation in vivo [17, 21-27]. Implantation of acrylated HA hydrogel with BMP-2 accelerates bone repair in calvarial defects in rats, and injectable hydrazone-crosslinked HA hydrogels with BMP-2 stimulate bone formation in rat calvaria [28]. In this study, we developed an injectable and immediately cured IFH/HA material. IFH-HA combined with BMP-2 promoted bone formation and bone union in a mouse refractory fracture model. IFH-HA, which possesses the advantages of injectable and implantable materials, may improve the success of bone healing and minimize the occurrence of possible side effects due to diffusion from HA hydrogel in situ. IFHHA/BMP-2 may therefore be a promising material for promoting refractory fracture repair in clinical settings.

BMP-2 signaling is initiated early on in the first phase of bone healing and leads to inflammatory response and periosteal activation. BMP-2 is additionally important at later phases of chondro- and osteogenesis [29-31]. Therefore, long-term sustained release of BMP-2 is important for accelerating bone formation during fracture healing. In our study, $23 \%$ of the administered dose of BMP-2 was released from IFH-HA in $4 \mathrm{~h}$. Subsequently, however, the release rate dropped to a moderate level, with approximately $100 \mathrm{ng} / \mathrm{ml}$ BMP-2-equivalent to the amount required to increase the ALP activity of mesenchymal stem cells [32,33]-released between 2 to 3 weeks in vitro. BMP-2 stimulates osteoblastic differentiation via the transcription factor, Osx [33, 34]. In our study, mRNA expression of Osx and differentiation markers Alpl and Bglap were increased in calluses even 6 weeks after BMP-2 administration. Therefore, IFHHA/BMP-2 may stimulate bone formation even at low doses in later phases of osteogenesis during fracture healing. Taken together, our findings suggest that IFHHA/BMP-2 may be a useful material for enhancing refractory fracture healing in clinical settings.

Several limitations of the present study warrant mention. First, we did not determine the distribution of hydrogel or BMP-2 in vivo or the precise mechanism underlying the acceleration of bone formation following application of IFH-HA/BMP-2. Second, we did not conduct comparisons with previously reported bioactive materials [35-37]. Finally, future studies should test BMPreleasing hydrogel in critical size defects, where large quantities of new bone are needed and longer healing periods are available due to the nonunion nature of these defects.

\section{Conclusion}

We examined the osteogenesis-promoting ability of HA gel containing BMP-2 in a mouse refractory fracture model. Fracture sites injected with HA/BMP-2 showed significantly greater bone volume, bone mineral content, and bone union compared with sites receiving no treatment or treated with HA alone. IFH-HA/BMP-2 may contribute to the treatment of refractory fractures. 


\section{Supplementary information}

Supplementary information accompanies this paper at https://doi.org/10. 1186/s13018-020-01953-7.

Additional file 1: Figure 1. Fracture healing process in non-cauterized and cauterized fracture mouse models.

\section{Abbreviations}

BMP-2: Bone morphogenetic protein-2; HRP: Horseradish peroxidase; IFHs: In situ-formed hydrogels; HA: Hyaluronic acid; GAGs: Glycosaminoglycans; TA: Tyramine hydrochloride; CMC: Carboxymethyl cellulose; PCR: Polymerase chain reaction; Alpl: Alkaline phosphatase; Bglap: Osteocalcin; Osx: Osterix; ELISA: Enzyme-linked immunosorbent assay; SE: Standard error

\section{Acknowledgements}

We thank Ms. Yuko Onuki for her help with real time PCR analysis.

\section{Authors' contributions}

SS, KU, and MT designed the study and analyzed the data. SS and KU wrote the manuscript. SS, WS, HS, GI, MM, KT, and YY participated in data collection, analysis, and interpretation. All authors read and approved the final manuscript.

\section{Funding}

This study was supported in part by JSPS KAKENHI grant Nos. 17 K16701, 17 K10982, and 18 K09079.

\section{Availability of data and materials}

The datasets supporting the conclusions of this article are included within the article. The raw data can be requested from the corresponding author.

\section{Ethics approval and consent to participate}

All experimental protocols were approved by the Kitasato University School of Medicine Animal Care Committee (permission number 2018-084; 2019-127).

\section{Consent for publication}

Not applicable

\section{Competing interests}

The authors declare that they have no competing interests.

Received: 15 November 2019 Accepted: 9 September 2020 Published online: 18 September 2020

\section{References}

1. Buza JA III, Einhorn T. Bone healing in 2016. Clin Cases Miner Bone Metab. 2016;13(2):101-5.

2. Einhorn TA. Enhancement of fracture-healing. J Bone Joint Surg Am. 1995; 77(6):940-56.

3. Nakajima F, Nakajima A, Ogasawara A, Moriya H, Yamazaki M. Effects of a single percutaneous injection of basic fibroblast growth factor on the healing of a closed femoral shaft fracture in the rat. Calcif Tissue Int. 2007; 81(2):132-8

4. Aro HT, Govender S, Patel AD, et al. Recombinant human bone morphogenetic protein-2: a randomized trial in open tibial fractures treated with reamed nail fixation. J Bone Joint Surg Am. 2011;93(9):801-8.

5. Govender S, Csimma C, Genant HK, et al. Recombinant human bone morphogenetic protein-2 for treatment of open tibial fractures: a prospective, controlled, randomized study of four hundred and fifty patients. J Bone Joint Surg Am. 2002;84-A(12):2123-34.

6. Kawaguchi $\mathrm{H}$, Oka $\mathrm{H}$, Jingushi $\mathrm{S}$, et al. A local application of recombinant human fibroblast growth factor 2 for tibial shaft fractures: a randomized, placebo-controlled trial. J Bone Miner Res. 2010;25(12):2735-43.

7. Carragee EJ, Chu G, Rohatgi $R$, et al. Cancer risk after use of recombinan bone morphogenetic protein-2 for spinal arthrodesis. J Bone Joint Surg Am. 2013;95(17):1537-45

8. Mesfin A, Buchowski JM, Zebala LP, et al. High-dose rhBMP-2 for adults: major and minor complications: a study of 502 spine cases. J Bone Joint Surg Am. 2013;95(17):1546-53.
9. Uchida K, Inoue G, Matsushita O, et al. Basic fibroblast growth factoranchored multilayered mesenchymal cell sheets accelerate periosteal bone formation. Biomed.Res.Int. 2017;2017:4371460.

10. Sekiguchi $\mathrm{H}$, Uchida $\mathrm{K}$, Inoue $\mathrm{G}$, et al. Acceleration of bone formation during fracture healing by poly(pro-hyp-gly) 10 and basic fibroblast growth factor containing polycystic kidney disease and collagen-binding domains from Clostridium histolyticum collagenase. J Biomed Mater Res A. 2016;104(6): 1372-8.

11. Chen F, Yu S, Liu B, et al. An injectable enzymatically crosslinked carboxymethylated pullulan/chondroitin sulfate hydrogel for cartilage tissue engineering. Sci Rep. 2016;6:20014

12. Jin R, Teixeira LS, Dijkstra PJ, et al. Injectable chitosan-based hydrogels for cartilage tissue engineering. Biomaterials. 2009;30(13):2544-51.

13. Jin R, Moreira Teixeira LS, Dijkstra PJ, Zhong Z, van Blitterswijk CA, Karperien M, Feijen J. Enzymatically crosslinked dextran-tyramine hydrogels as injectable scaffolds for cartilage tissue engineering. Tissue Eng Part A. 2010;16(8):2429-40.

14. Jukes JM, van der Aa LJ, Hiemstra C. van VT, Dijkstra PJ, Zhong Z, Feijen J, van Blitterswijk CA, de BJ. A newly developed chemically crosslinked dextran-poly(ethylene glycol) hydrogel for cartilage tissue engineering. Tissue Eng Part A. 2010;16(2):565-73.

15. Jin R, Moreira Teixeira LS, Dijkstra PJ, van Blitterswijk CA, Karperien M, Feijen J. Chondrogenesis in injectable enzymatically crosslinked heparin/dextran hydrogels. J Control Release. 2011;152(1):186-95.

16. Jin R, Teixeira LS, Dijkstra PJ, van Blitterswijk CA, Karperien M, Feijen J. Enzymatically-crosslinked injectable hydrogels based on biomimetic dextran-hyaluronic acid conjugates for cartilage tissue engineering. Biomaterials. 2010;31(11):3103-13.

17. Huang H, Feng J, Wismeijer D, Wu D, Hunziker EB. Hyaluronic acid promotes the osteogenesis of BMP-2 in an absorbable collagen sponge. Polymers. 2017:9:339.

18. Lee F, Chung JE, Kurisawa M. An injectable hyaluronic acid-tyramine hydrogel system for protein delivery. J Control Release. 2009;134(3):186-93.

19. Sekiguchi H, Uchida K, Matsushita O, et al. Basic fibroblast growth factor fused with tandem collagen-binding domains from Clostridium histolyticum collagenase ColG increases bone formation. Biomed Res Int. 2018;2018: 8393194.

20. Naruse K, Sekiya H, Harada Y, et al. Prolonged endochondral bone healing in senescence is shortened by low-intensity pulsed ultrasound in a manner dependent on COX-2. Ultrasound Med Biol. 2010;36(7):1098-108.

21. Kisiel M, Klar AS, Ventura M, et al. Complexation and sequestration of BMP-2 from an ECM mimetic hyaluronan gel for improved bone formation. PLOS One. 2013;8(10):e78551.

22. Todeschi MR, El Backly RM, Varghese OP, et al. Host cell recruitment patterns by bone morphogenetic protein-2 releasing hyaluronic acid hydrogels in a mouse subcutaneous environment. Regen.Med. 2017;12(5): 525-39.

23. Kim SK, Cho TH, Han JJ, et al. Comparative study of BMP-2 alone and combined with VEGF carried by hydrogel for maxillary alveolar bone regeneration. Tissue Eng Regen Med. 2016;13(2):171-81.

24. Martinez-Sanz E, Ossipov DA, Hilborn J, et al. Bone reservoir: injectable hyaluronic acid hydrogel for minimal invasive bone augmentation. J Control Release. 2011;152(2):232-40.

25. Eckardt $\mathrm{H}$, Christensen KS, Lind $\mathrm{M}$, et al. Recombinant human bone morphogenetic protein 2 enhances bone healing in an experimental model of fractures at risk of non-union. Injury. 2005;36(4):489-94.

26. Lee JH, Kim J, Baek HR, et al. Fabrication of an rhBMP-2 loaded porous betaTCP microsphere-hyaluronic acid-based powder gel composite and evaluation of implant osseointegration. J Mater Sci Mater Med. 2014;25(9):2141-51.

27. Zhang $Y$, Chen $H$, Zhang $T$, et al. Injectable hydrogels from enzymecatalyzed crosslinking as BMSCs-laden scaffold for bone repair and regeneration. Mater Sci Eng C Mater Biol Appl. 2019;96:841-9.

28. Hulsart-Billstrom G, Bergman K, Andersson B, et al. A uni-cortical femoral defect model in the rat: evaluation using injectable hyaluronan hydrogel as a carrier for bone morphogenetic protein-2. J Tissue Eng Regen Med. 2015: 9(7):799-807.

29. Cho TJ, Gerstenfeld LC, Einhorn TA. Differential temporal expression of members of the transforming growth factor beta superfamily during murine fracture healing. J Bone Miner Res. 2002;17(3):513-20.

30. Lienau J, Schmidt-Bleek K, Peters A, et al. Insight into the molecular pathophysiology of delayed bone healing in a sheep model. Tissue Eng Part A. 2010;16(1):191-9. 
31. Niikura T, Hak DJ, Reddi AH. Global gene profiling reveals a downregulation of BMP gene expression in experimental atrophic nonunions compared to standard healing fractures. J Orthop Res. 2006;24(7):1463-71.

32. Cha JK, Lee JS, Kim MS, et al. Sinus augmentation using BMP-2 in a bovine hydroxyapatite/collagen carrier in dogs. J Clin Periodontol. 2014;41(1):86-93.

33. Kadowaki A, Tsukazaki T, Hirata K, et al. Isolation and characterization of a mesenchymal cell line that differentiates into osteoblasts in response to BMP-2 from calvariae of GFP transgenic mice. Bone. 2004;34(6):993-1003.

34. Celil AB, Campbell PG. BMP-2 and insulin-like growth factor-I mediate Osterix (Osx) expression in human mesenchymal stem cells via the MAPK and protein kinase D signaling pathways. J Biol Chem. 2005;280(36):31353-9.

35. Horvathy DB, Vacz G, Szabo T, et al. Serum albumin coating of demineralized bone matrix results in stronger new bone formation. $J$ Biomed Mater Res B Appl Biomater. 2016;104(1):126-32.

36. Maisani M, Sindhu KR, Fenelon M, et al. Prolonged delivery of BMP-2 by a non-polymer hydrogel for bone defect regeneration. Drug Deliv Transl Res. 2018;8(1):178-90.

37. Seo BB, Koh JT, Song SC. Tuning physical properties and BMP-2 release rates of injectable hydrogel systems for an optimal bone regeneration effect. Biomaterials. 2017:122:91-104.

\section{Publisher's Note}

Springer Nature remains neutral with regard to jurisdictional claims in published maps and institutional affiliations.

Ready to submit your research? Choose BMC and benefit from:

- fast, convenient online submission

- thorough peer review by experienced researchers in your field

- rapid publication on acceptance

- support for research data, including large and complex data types

- gold Open Access which fosters wider collaboration and increased citations

- maximum visibility for your research: over $100 \mathrm{M}$ website views per year

At $\mathrm{BMC}$, research is always in progress.

Learn more biomedcentral.com/submissions 